\title{
Binding Component Selection and Development of Technology for Granulation of Carbon-Containing Mixtures (Graphite)
}

\author{
Maksym Skydanenko ${ }^{1}$, Yuliia Kurdes $^{2}$, Mykolo Kononenko ${ }^{3}$, Marenok Vitaliy ${ }^{4}$ \\ 1, 2, 3,4 Processes and Equipment of Chemical and Petroleum-Refineries Department, Sumy State \\ University, UKRAINE, Sumy. Rymskogo-Korsakova street 2, \\ E-mail: 1.m.skydanenko@pohnp.sumdu.edy.ua; 2.kurdesylia@gmail.com; 3.konp2006@ukr.net
}

\begin{abstract}
The parameters influencing physical and chemical properties of granules are determined and studied in the article. It is conducted optimal selection of organic and mineral binding substances and their mixtures using which the production technology is worked out and fulfilled.
\end{abstract}

Key words - granulation, plate granulator, balling, carbon-containing mixtures, graphite, granule.

\section{I.Introduction}

Graphite is an important material at the market worldwide. It is widely used in the industry and production, which is explained by its unique properties. It is resistant both to natural and chemical influence and it has high conductivity, durability and low hardness. Under the temperature influence graphite tends to solidify. It is used for moulding parts to eliminate defective goods number. This material is good for lubricating the parts to reduce burning-in. Graphite is used in the atomic industry; it is essential in the color and chemical industries. It is also used for the construction of electric furnaces. Graphite is used for the manufacture of the most important spare parts for household appliances.

In the domestic industry, graphite is used in the manufacture of bearings [1], electric brushes, galvanic batteries, rings of friction and many others.

Granular graphite is widely used in metallurgical industry. Its use is appropriate in cases when it is necessary to dissolve material in the shortest possible time, while the role of temperature is essential.

Granular graphite is also used:

- For saturation of steel and cast iron with carbon [2];

- As a filler for various graphite plastics;

- As a protective material during continuous casting of metal;

- For improvement of the ecological situation in production (metallurgy) [3];

- As a raw material for the production of graphitized carbon materials [4].

Based on this rather wide application scope, it's worth saying that granular graphite is a popular material that is in demand. There are no analogs to graphite in modern industry nowadays. In order to compete in the international industrial market with the world's companies, it is necessary to improve the product quality. The research purpose was to obtain granular graphite with the following chracteristics: spherical granules of size 2-3 $\mathrm{mm}$, durability of granules $-0,8 \mathrm{MPa}$ min, ash content $-2 \%$ max.

\section{Methodology for Conducting Laboratory Tests}

The number of medium-sized enterprises is growing worldwide and such mediumsized and small enterprises that have the ability to change the production range quickly depending on the requirements of the customer, are becoming more and more popular. Granular graphite is a product that can be efficiently produced by such enterpises. The 
most optimal way of obtaining graphite granules of spherical shape is the method of "balling" with the use of liquid binding solutions.

Laboratory studies on the selection of binding substances and processing of the technological parameters of obtaining granular carbon containing mixture (graphite) were carried out in three stages:

- the first stage: selection of the binding mixture composition;

- the second stage: examining of influence of the binding substance composition and technological parameters of granulation and drying on the properties of the finished granular product;

- the third stage: checking of the optimal binding substance composition and technological parameters of the granulation equipment operation in the continuous granulation mode; preparing of the laboratory experimental lot of the granular product.

Dried granular product was tested to determine the granulometric composition by sieving in accordance with GOST 21560.1. Static strength of the granules was tested according to GOST 21560.2 standards and the ash content of the granules - according to GOST 11022.

\section{Experimental Stand}

An experimental stand was designed to conduct a research, which enables to carry out all the tasks of experimental study. The schematic diagram of the experimental stand is shown in Fig.1



Fig.1. Basic Scheme of the Experimental Stand

The laboratory stand consists of the following equipment units: B - pressure tank for a binding solution; C -compressor; Gr - plate granulator; $\mathrm{T}$ - tray; Dc - drying cabinet.

The initial powdered material (graphite) was fed directly to a granulator of the type BP40C02 on the surface of which, using a sprayer, one applied a binding solution supplied from the pressure tank. Binding solution is delivered from the pressure tank to the sprayer with compressed air. Compressed air is pumped into the tank with the compressor Metabo 100L through the gas rotameter VA-40 produced by Krohne Messtechnik GmbH \& Co K. 
The binding solution was fed through liquid rotameters VA-40 by Krohne. Finished granules were poured out of the granulator and came into the tray, thereafter they were dried in a drying cabinet Binder ED 23. The spraying process was carried out at air flow rate of 0.04 to $0.3 \mathrm{~m}^{3} / \mathrm{hr}$ and liquid flow rate was from 10 to $50 \mathrm{l} / \mathrm{h}$.

\section{Results}

In the course of research, composition of the binding solution was selected. In the process of granulation, such parameters as granule formation rate, granulometric composition, strength of wet granules, quality of individual granule surface, strength of dried granules, and ash content of granules were studied and measured.

The content of tested binding solutions and results of laboratory studies are given in Table 1.

Table 1. Results of Laboratory Research on the Selection of Binding Solutions

\begin{tabular}{|c|c|c|c|c|c|c|c|c|c|c|c|c|c|c|}
\hline \multirow{3}{*}{ 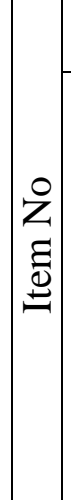 } & \multicolumn{6}{|c|}{ Binding solution composition } & \multirow{3}{*}{ 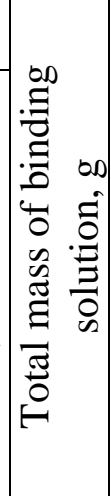 } & \multirow{3}{*}{  } & \multirow{3}{*}{ 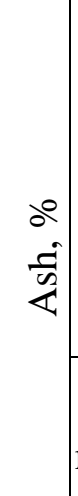 } & \multirow{2}{*}{\multicolumn{5}{|c|}{$\begin{array}{l}\text { Granulometric } \\
\text { composition, } \mathrm{g}\end{array}$}} \\
\hline & \multirow{2}{*}{ 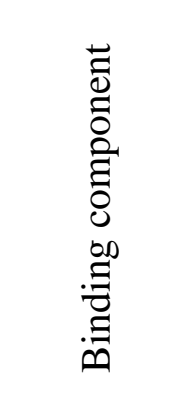 } & \multirow{2}{*}{ 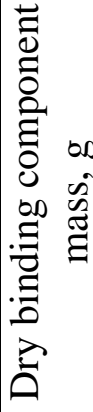 } & \multirow{2}{*}{ 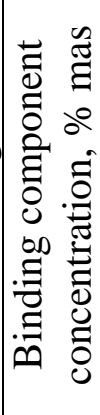 } & \multirow{2}{*}{$\begin{array}{l}\frac{1}{0} \\
\frac{2}{0} \\
\mathscr{2}\end{array}$} & \multirow{2}{*}{ 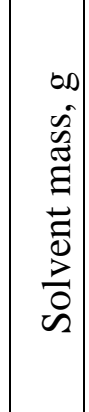 } & \multirow{2}{*}{ 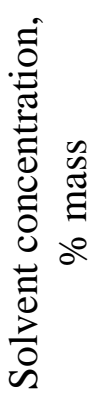 } & & & & & & & & \\
\hline & & & & & & & & & & $\begin{array}{l}>5 \\
\mathrm{~mm}\end{array}$ & $\begin{array}{l}3-5 \\
\mathrm{~mm}\end{array}$ & $\begin{array}{l}2-3 \\
\mathrm{~mm}\end{array}$ & $\begin{array}{c}1-2 \\
\mathrm{~mm}\end{array}$ & $\begin{array}{l}<1 \\
\mathrm{~mm}\end{array}$ \\
\hline 1 & A & 3,4 & 10,7 & ater & 27,4 & 86,6 & 31,62 & 1,25 & \begin{tabular}{|r|}
$0,8-$ \\
0,9 \\
\end{tabular} & 5 & 16 & 40 & 13 & 122 \\
\hline 2 & $\begin{array}{c}\text { Organic } \\
\text { binding- } \\
\text { subtance } 1\end{array}$ & 30 & 48,5 & er & 31 & 50,1 & 61,9 & 0,69 & 1,9 & 21 & 77 & 27 & 6 & 79 \\
\hline 3 & Cleolum & 50 & - &  & - & - & 50 & 0,88 & 1,6 & 3 & 62 & 54 & 13 & 92 \\
\hline 4 & $\begin{array}{c}\text { Alkali } \\
\text { salt }\end{array}$ & 1,8 & 4,9 & water & 34,8 & - & 37,03 & 1,5 & 9 & 14 & 61 & 34 & 12 & 98 \\
\hline 5 & Resina & 11 & 13 & nol & 72 & 86,7 & 83 & 0,16 & - & 11 & 9 & 2 & 2 & 72 \\
\hline 6 & $\begin{array}{c}\text { Organic } \\
\text { binding- } \\
\text { subtance } 2\end{array}$ & $\begin{array}{c}10 \\
5\end{array}$ & 12 & water & 20 & 75 & 30 & 0,15 & 1,6 & 54 & 10 & 3 & 1 & 53 \\
\hline
\end{tabular}

\section{Analysis of the Results}

Based on the research results on the binding substances selection for granulation by balling of carbon containing powder (graphite), the following conclusions are made.

Alkali metal salt solution and organic binding component provided the highest strength of the finished granules and good granule formation. Though the use of alkali metal salt solution provided high strength of the granulated product, ash analysis showed that the use of this solution as a binding component results in a significant percentage of non-combustible residue, which is not allowed for this type of granular product.

High-performance characteristics have acetate-based binding solutions. These binding solutions provide high static granule strength and abrasion resistance. 
Experiments on granulation of powders showed high quality of granular products made using binding solutions based on cleolum, including low ash content and absence of self-ignition when heated to high temperatures.

Using of organic binding component is the best solution for the production of granular products from carbon containing mixtures. It provides good granule formation, high strength of granular products and acceptable ash content of the finished product. Increasing the organic binding substance content in the granular product improves the granule strength, but enhances the content of non-combustible residues.

Experimental works on the use of other binding components (resin alcohol solution, modified starch, etc.) did not show consistant results.

\section{Conclusion}

Based on the results of experimental work on the granulation of carbon containing powders at the laboratory stand, the following conclusions can be made.

1) The optimal composition of the binding solution should contain 30-34\% of organic binding component mass. As a solvent, it is recommended to use softened water.

2) In order to achieve the complete processing of raw materials into the target fraction of the finished product, it is recommended to use a return mechanism in the production line consisting of granule classifier, crusher, and transport equipment. The main task of the return mechanism is to carry out target fraction of the granulated product from the device and to return the non-conforming product to the beginning of the process cycle.

3) Studies on the application of other granulation equipment types will enable to obtain granular graphite with other parameters.

4) Drying process of the finished granular material is recommended to fulfill at the temperature of $160^{\circ} \mathrm{C}$, which ensures high strength of the finished product. Further studies of the drying process dynamics will make it possible to determine its optimal technological parameters.

\section{References}

[1] Y. Hirai, T. Sato, T. Fukui, K. Yamada, K. Tanizawa, H. Usami, "Effect of surface groove and graphite penetration on friction properties of sulfide containing copper alloy journal bearing in dry condition. Procedia Engineering" 2013, Vol.68, pp. 3742.

[2] A. R. Kiani-Rashid, S. A. Rounaghi, "The New Methods of Graphite Nodules Detection in Ductile Cast Iron", Materials and Manufacturing Processes, 2011, Vol.26(2), pp242 - 248.

[3] Golly, Benjamin et al. "Large chemical characterisation of PM10 emitted from graphite material production: Application in source apportionment." The Science of the total environment, 2015, Vol. 538, pp. 634-43.

[4] M.K. Skakov, Sh.R. Kurbanbekov, Y.T. Koyanbaev, et al. "Siliconized Graphite Production Technology" Proceedings of the 2015 AASRI International Conference on Circuits and Systems, 2015, pp. 215-218. 